LA-UR- $99-18$

Title: VALUE OF GLOBAL WEATHER SENSORS

Author(s): Gregory H. Canavan, P-DO

Submitted to:

For discussions outside the Laboratory

MASTER

Date: 23 December 1998

DESTRIBUTOW OF THS DOCUMENT IS UNLFHTED



Los Alamos National Laboratory, an affirmative action/equal opportunity employer, is operated by the University of California for the U.S. Department of Energy under contract W-7405-ENG-36. By acceptance of this article, the publisher recognizes that the U.S. Government retains a nonexclusive, royalty-free license to publish or reproduce the published form of this contribution, or to allow others to do so, for U.S. Government purposes. The Los Alamos National Laboratory requests that the publisher identify this article as work performed under the auspices of the U.S. Department of Energy. 


\section{DISCLAIMER}

This report was prepared as an account of work sponsored by an agency of the United States Government. Neither the United States Government nor any agency thereof, nor any of their employees, makes any warranty, express or implied, or assumes any legal liability or responsibility for the accuracy, completeness, or usefulness of any information, apparatus, product, or process disclosed, or represents that its use would not infringe privately owned rights. Reference herein to any specific commercial product, process, or service by trade name, trademark, manufacturer, or otherwise does not necessarily constitute or imply its endorsement, recommendation, or favoring by the United States Government or any agency thereof. The views and opinions of authors expressed herein do not necessarily state or reflect those of the United States Government or any agency thereof. 


\section{DISCLAIMER}

Portions of this document may be illegible in electronic image products. Images are produced from the best available original document. 


\title{
VALUE OF GLOBAL WEATHER SENSORS
}

\author{
Gregory H. Canavan
}

Constellations of small transponders could measure vector wind fields with sufficient accuracy for $\sim$ two week forecasts. The benefits of such forecasts are much larger than the cost of the sensors.

Long-range weather predictions have great scientific and economic potential, ${ }^{1}$ but require precise global observations. Small balloon "transponders" could serve as Lagrangian trace particles to measure the vector wind, which is the primary input to long-range numerical forecasts. ${ }^{2}$ The wind field is difficult to measure; it is at present poorly sampled globally. Distance measuring equipment (DME) triangulation of signals from roughly a million transponders could sample it with sufficient accuracy to support $\sim$ two week forecasts. Such forecasts would have great scientific and economic potentialwhich is estimated below. DME uses small, low-power transmitters on each transponder to broadcast short, low-power messages that are detected by several small receivers and forwarded to the ground station for processing of position, velocity, and state information. Thus, the transponder is little more than a balloon with a small radio, which should only weigh a few grams and cost a few dollars. Store and forward satellites or high altitude balloons should weigh a few $\mathrm{kg}$ and cost $\sim \$ 1 \mathrm{~K}-1 \mathrm{M}$. $^{3}$

Scaling estimates indicate that an average $\sim 50 \mathrm{~km}$ spacing between transponders should support $\sim 2$ week weather forecasts. ${ }^{4}$ Moreover, those estimates are based on turbulence theories that could significantly underestimate the predictability of the atmosphere. Measuring winds with $\sim 1$ $\mathrm{m} / \mathrm{s}$ accuracy required for two week forecasts within the time cycle for their re-initialization requires balancing the transponder and satellite constellations. Imperfect knowledge of small flow features represents a source of errors, which corrupt the larger scales of interest. Global scales are largely two dimensional, so errors propagate to scales a factor of two larger in about a day. Thus, higher resolution can forestall their corruption; however, that involves finer observations and numerical forecasts. The value of longer range forecasts increase and then asymptote. Equating their marginal costs and benefits determines the optimal forecast duration and resolution. The times increase and the resolutions decrease with increasing economic value, although they are limited by increasing computational costs and three dimensional effects.

Review of sensor scaling. The DME system has one constellation of tropospheric transponders and another of high altitude balloon or satellite receivers. Each transponder has a radio, power supply, and balloon, which scale with radio power as $\mathrm{pP}$, where $\mathrm{p}$ is a scaling constant $\sim \$ 1 \mathrm{~K} / \mathrm{W}$. Achieving horizontal resolution $\mathrm{r}$ requires ${ }^{5}$

$$
N_{T} \sim 4 \pi R_{e}{ }^{2} / \pi r^{2},
$$


transponders, where $R_{e}$ is the Earth's radius and $r=$ resolution $/ 2$ is the effective radius of the area sampled by each transponder. Thus, $50 \mathrm{~km}$ resolution, or $\mathrm{r}=25 \mathrm{~km}$, requires $\sim 4(6400 / 25)^{2} \sim$ 260,000 transponders. The total cost of the transponders is

$$
\mathrm{C}_{\mathrm{T}}=\mathrm{pPN}_{\mathrm{T}} \sim 4 \mathrm{pPN}_{\mathrm{T}} \mathrm{R}_{\mathrm{e}}^{2} / \mathrm{r}^{2}
$$

Each receiver balloon or satellite has a bus, GPS receiver, and a transmitter for forwarding data to the ground, which are assumed to scale on a parameter A representing the effective receiver aperture or bus area, so the cost of a satellite is $\sim \mathrm{aA}$, where $\mathrm{a}$ is a scaling coefficient. DME determination of position and time requires 4 satellites in view. If the receivers are at altitude $h$, the size of the satellite constellation required is

$$
\mathrm{N}_{\mathrm{S}} \sim 8\left(\mathrm{R}_{\mathrm{e}}+\mathrm{h}\right) / \mathrm{h} \text {. }
$$

The scaling with $h$ is studied elsewhere; here, it is assumed that $h \ll R_{e}$, for $N_{s} \sim 8 R_{e} / h$. For omnidirectional radios, achieving adequate signal to noise $S / N$ requires that

$$
\mathrm{PA} / \mathrm{R}^{2} \geq \mathrm{K}
$$

where $\mathrm{K} \sim 5 \times 10^{-18}$ Joule and the constraint is taken to be an equality and required to hold for the satellites on the horizon. With this constraint the total cost becomes

$$
\mathrm{C}=\mathrm{C}_{\mathrm{T}}+\mathrm{C}_{\mathrm{A}}=\mathrm{pPN}_{\mathrm{S}}+\mathrm{aAN} \mathrm{N}_{\mathrm{S}}=\mathrm{pN}_{\mathrm{S}} \mathrm{KR}^{2} / \mathrm{A}+\mathrm{aAN} \text {. }
$$

which is minimized by the choices $A_{0}=\sqrt{ }\left(K_{p N} N_{T} / N_{S} a\right)$ and $P_{0}=\sqrt{ }\left(K_{a N} / N_{T} p\right) R$, which give

$$
C=C_{T}+C_{A}=2 \sqrt{ }\left(\operatorname{KapN}_{T} N_{S}\right) R \text {. }
$$

in which equal amounts are spent on transducers and satellites, independent of the parameters used and dependent only on the assumed linearity of costs and the bilinear constraint on $P$ and $A$. For $h$

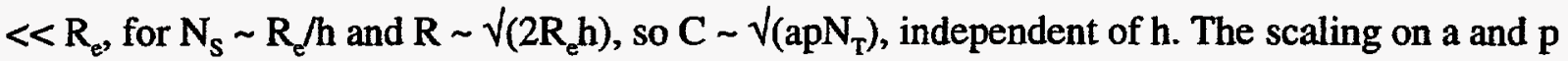
was studied earlier. By Eq. (1), the scaling on $\mathrm{r}$ is $\mathrm{C} \sim \mathrm{C}^{\prime} / \mathrm{r}$, where $\mathrm{C}^{\prime}$ 'is a constant that can be estimated from the hardware costs of $\sim \$ 100 \mathrm{M}$ for $50 \mathrm{~km}$ resolution to be $C^{\prime} \sim \$ 100 \mathrm{M}(50 \mathrm{~km} / 2) \sim$ $\$ 2.5 B-\mathrm{km}$. This should be the dominant cost for $\mathrm{r} \sim 25 \mathrm{~km}$, but for much smaller scales, the cost of reducing the data and performing the forecasts will become significant. The latter increases as $1 / \mathrm{r}^{3}$ due to the amount of grid points in the calculations and by another factor of $1 / \mathrm{r}$ due to the smaller time steps needed, for an overall increase of $1 / r^{4}$. The calculations below use $1 / r^{n}$, where $n$ varies from $\sim 1$ in the next decade to $\sim 4$ in subsequent decades, so that

$$
\mathrm{C}=\mathrm{C}^{\prime} / \mathrm{r}^{\mathrm{n}} \approx \$ 100 \mathrm{M}(25 \mathrm{~km})^{\mathrm{n}} / \mathrm{r}^{\mathrm{n}} \text {, }
$$

which is shown in Fig. 1 for minimum certain turbulent eddy scale size $D \approx 2 r$ ranging from 8 to $2,500 \mathrm{~km}$. The curve with the smallest slope is for $n=1$, i.e., costs dominated by sensors. It increases from $\sim \$ 1 \mathrm{M}$ at $\sim 1,000 \mathrm{~km}$ to about $\$ 500 \mathrm{M}$ at $\mathrm{D} \sim 8 \mathrm{~km}$. As $\mathrm{n}$ increases, the slopes increase and the curves rotate clockwise about the scaling point. For $\mathrm{D}=8 \mathrm{~km}$, the computation dominated curve for $n=4$ approaches $\$ 100 B$.

The variation of $\mathrm{C}$ with $\mathrm{r}$ is determined by differentiation to be

$$
\mathrm{dC} / \mathrm{dr}=-\mathrm{nC} / \mathrm{r}^{\mathrm{n}+1} \text {, }
$$


which is shown in Fig. 2. Again the curve with the smallest slope is for $\mathbf{n}$ It increases from $-\$ 0.01 \mathrm{M} / \mathrm{km}$ at $\sim 1,000 \mathrm{~km}$ to about $\$ 100 \mathrm{M} / \mathrm{km}$ at $\mathrm{D} \sim 8 \mathrm{~km}$. As $\mathrm{n}$ increases, the curves again rotate For $\mathrm{D}=8 \mathrm{~km}$, the computation dominated curve for $\mathrm{n}=4$ approaches $\$ 100,000 \mathrm{~B} / \mathrm{km}$.

Predictability. Imperfect knowledge of flow features with scales smaller than $D=2 r$ represents a source of errors that propagate to corrupt prediction of the larger scales of interest. In the largely two dimensional flows on the Earth's surface, errors propagate to scales a factor of two larger in about a day. When this cascade of errors reaches the large scales of interest, the forecast is invalidated. Finer resolution forces error growth to start at smaller scales and levels, which delays the time at which the forecast is corrupted.

Theoretical treatments provide an estimate of the time it takes for errors to propagate from inertial range eddies of length scales $D \sim 10-100 \mathrm{~km}$ to the largest planetary flow scales $L \approx 5,000$ $\mathrm{km}$ of interest for long-range predictions, which is

$$
t=b[\ln (L / D)]^{2 / 3} \text {, }
$$

which is shown in Fig. 3 for three curves are for values of the constant $b$ determined by the Lagrangian history direct interaction approximation for homogeneous two-dimensional turbulent flows. The nominal value is $b \approx 4.5$ days. The value $b \approx 3.6$ days results from the assumption of weak turbulence sweeping out of errors; $b \approx 5.2$ from the assumption of strong sweeping out. The three values roughly bound the range of values inferred from planetary flows and numerical experiments.

The uncertainty is small at large $D$ because $t$ is short there. At $D \sim 3 \mathrm{~km}$ is $4-5$ days because $t$ $\sim$ 2-3 weeks there. The slope is greatest at large $D$ and decreases smaller for smaller $D$; thus, forecasting gains are greatest at large $\mathrm{D}$ and diminish for smaller, although they remain significant for all D. For analytic convenience, a fit to the predictability time is used below

$$
\mathrm{t} \approx \mathrm{A}+\mathrm{B} \ln (\mathrm{L} / \mathrm{D}) \text {, }
$$

in which $B \approx 1.9$ days is and $A \approx 3.8$ days. Figure 4 compares this approximation with $t$ from $E q$. (10) for the corresponding nominal b. Agreement is good for D from 10 to $1,000 \mathrm{~km}$. The $\sim 1$ day discrepancy at $3,000 \mathrm{~km}$ is not important, as current experience has bounded predictability there. The $\sim 5 \%$ discrepancy at $3 \mathrm{~km}$ is unimportant because those scales are smaller than the scale height; hence, they are three dimensional, so turbulence and predictability scale more weakly on $\mathrm{D}$.

Value. The value of long-range forecasts is estimated in earlier reports. ${ }^{6}$ Two-week forecasts are currently estimated to have value $\mathrm{V}_{0} \sim \$ 100 \mathrm{~B} / \mathrm{yr}$. As these benefits are aggregated over a number of economic sectors with widely varying time scales, it is likely that the benefits will increase with the time, $t$, for which the forecast is valid and saturate at the asymptotic level $V_{0}$. An approximate representation of this scaling is

$$
\mathrm{V} \approx \mathrm{V}_{\mathrm{o}}\left(1-\mathrm{e}^{\mathrm{t} \mathrm{T}}\right)
$$

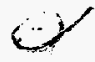

where $\mathrm{T}$ is the lead time needed for maximum economic effect,, which is $\approx 1-4$ weeks, depending 
on the sector of the economy. Substituting Eq. (10) into (11) produces

$$
\mathrm{V} \approx \mathrm{V}_{\mathrm{o}}\{1-\exp [-\mathrm{A} / \mathrm{T}-\mathrm{B} \ln (\mathrm{L} / \mathrm{D}) / \mathrm{T}]\} \approx \mathrm{V}_{\mathrm{o}}\left[1-\mathrm{e}^{-\mathrm{A} / \mathrm{T}}(\mathrm{D} / \mathrm{L})^{\mathrm{B} / \mathrm{T}}\right]
$$

which is shown in Fig. 5 as a function of $D$ for values of $T$ that span the different sectors of the economy. For $\mathrm{T}=7$ days, benefits grow quickly as $\mathrm{D}$ decreases, increasing from $\sim 50 \mathrm{~B}$ at 2,500 $\mathrm{km}$ to $\sim \$ 90 \mathrm{~B}$ at $8 \mathrm{~km}$. The increase in $\mathrm{V}$ is smaller for longer $\mathrm{T}$. For $\mathrm{T}=14$ days, the increase is from 30 to $70 \%$ of $V_{0}$. For 21 and 28 days, the increase only reaches about half $V_{0}$, although the absolute increase roughly doubles in each case. The derivative of $\mathrm{V}$ with respect to $\mathrm{D}$ is

$$
\mathrm{dV} / \mathrm{dD}=-\mathrm{V}_{0} \mathrm{e}^{-\mathrm{A} T \mathrm{~T}} \mathrm{D}^{\mathrm{B} / \mathrm{T}-1} / \mathrm{L}^{\mathrm{B} / \mathrm{T}},
$$

which scales as $\sim D^{B / T-1}$. For $T=14$ days, $B / T \sim 1.9 / 14 \sim 0.14$, so the exponent of $D$ is $<0$, in accord with the shapes of the curves in Fig. 5.

Optimization. Improved resolution is useful to the point where its marginal benefit just justifies its marginal cost, $\mathrm{dC} / \mathrm{dr}=\mathrm{dV} / \mathrm{dr}$, which can be determined by equating Eqs. (8) and (13)

$$
D_{0}=\left[2^{n+1} n C^{\prime} e^{A T} L^{B / T} / V_{0}\right]^{1 /(B / T+n)} \text {, }
$$

which is shown in Fig. 6 for $n=1$, i.e., modest computational costs, and $T=7$ day response time. At $\mathrm{V}_{\mathrm{o}}=\$ 1 \mathrm{~B} / \mathrm{yr}$, the optimal $\mathrm{t}$ is $\approx 12$ days and the optimal resolution is $\approx 60 \mathrm{~km}$. As $\mathrm{V}_{\mathrm{o}}$ increases, the optimal $t$ increases, and $D_{0}$ falls rapidly. $B y V_{0}=\$ 3 B / y r, t \approx 13$ days and $D_{0} \approx 25 \mathrm{~km}$. By $V_{0}=$ $\$ 10 B / y r, t=16$ days and $D_{0} \approx 9 \mathrm{~km}$. Larger $V_{0}$ formally produce larger $t$, but those $t$ and resolutions involve three dimensional flows, where the weaker scaling of $t$ on $D$ must be included. Perhaps the principal observation from Fig. 6 is that for anticipated potential economic benefits, $t$ remains within the range thought theoretically attainable and $\mathrm{D}_{\mathrm{o}}$ remains within the resolutions possible with practical constellations of balloon transducers.

Figure 7 carries the results of Fig. 6 to much lower values of $V_{0}$. For $V_{0} \approx \$ 30 \mathrm{M} / y r, t \approx 7$ days, which is about the upper bound of current forecasts, and $D_{0} \approx 1,000 \mathrm{~km}$, which is roughly the average resolution of current regional observational networks. Thus, the scaling results estimated for these new constellations of global transducers connect smoothly to the empirical values for current systems.

An interesting feature of Fig. 7 is that the plot of $\log D_{0}$ versus $\log V_{0}$ is linear. That scaling follows from Eq.(14), which gives $\log D_{0} \sim-\log \left(V_{0}\right) /(n+B / T)$, so that from Eq. $(10), t \approx A+$ $B \ln (L / D) \sim A-B \log D_{0} \sim A+B \log \left(V_{0}\right) /(n+B / T)$, as seen. Thus, the optimal resolution is a unique, though nonlinear function of the benefit of predictions alone.

Figure 8 shows $\log \mathrm{D}_{\mathrm{o}}$ and $\mathrm{t}$ for the conditions of Fig. 6 and $\mathrm{n}=4$, i.e., high computational costs associated with high resolution. From Eq. (14), $D_{0} \sim 1 / V_{0}^{1 /(B / T+n)}$, so increasing $n$ reduces the exponent of $V_{0}$, which weakens the dependence of $D_{0}$ on $V_{0} . t$ only reaches 15 days and $D_{0} \sim 15$ $\mathrm{km}$ by $\mathrm{V}_{\mathrm{a}^{\circ}}=\$ 100 \mathrm{~B} / \mathrm{yr}$ as expected the greater cost of computations shifts the optimum to lower resolution, shorter predictions, and less benefits. Coamparing Figs. 6 and 8 indicates that $n$ is an important variable for any benefit over $\sim \$ 1 B$. 
An important and somewhat poorly defined parameter is $\mathrm{T}$, the time for which the forecast must hold to retain $63 \%$ of its total potential value. Figure 9 shows the scaling of $D_{0}$ and $t$ on the required prediction time $\mathrm{T}$. The dependence on $\mathrm{T}$ in $\mathrm{Eq}$. (14) is distributed and complex, but the result is fairly simple. For $\mathrm{T}$ small, $\mathrm{D}$ decreases with $\mathrm{T}$; and then levels out at about $10 \mathrm{~km}$ for $\mathrm{T} \geq$ 30 days for the parameters of Fig. 6. Conversely, for small $\mathrm{T}, \mathrm{t}$ increases roughly linearly with $\log T$, and then levels off at $\approx 15$ days for larger $T$. Simply put, when the benefits can be obtained with short range forecasts, only small $t$ and the correspondingly crude spatial resolution required is provided. If the benefits require long predictions, the forecast time increases with $T$ up to the maximum that is thought to be attainable and $\mathrm{D}$ is improved accordingly.

Summary and conclusions. Long-range weather predictions have great scientific and economic potential, but require global observations, which small balloons with transmitters for DME measurement could provide. For linear power and aperture scaling and conventional link sizing, costs for power, aperture, and the whole system scale linearly on range and more weakly on cost parameters. The resolution needed for two week forecasts would nominally cost about $\$ 100 \mathrm{M}$. Costs would increase for longer forecasts, but would be significantly less for the use of such sensors to globalize current resolution. The fabrication of balloons, transmitters, and power supplies with adequate lifetimes and cost involve risk, but they only enter cost estimates weakly. Most technology is available commercially.

Imperfect knowledge of small flow features represents a source of errors, which corrupt the larger scales of interest. Global scales are largely two dimensional, so errors propagate to scales a factor of two larger in about a day. Thus, measurements at finer resolution can forestall their corruption. However, finer resolution involves the expense of both finer observational grids and higher resolution numerical forecasts. The value of longer range forecasts increases and then asymptotes at some limiting value for each economic sector. Equating these marginal costs and benefits determines the optimal forecast duration and associated resolution for maximum incremental benefits.

The durations and resolutions so determined lie within those thought attainable and practical. The times increase and resolutions decrease with increasing economic value, although those trends are inhibited by increasing computational costs. They are strongly sensitive to the time the forecast must hold to produce its maximum value. If the benefits can be obtained with short range forecasts, small $t$ and crude resolution are used; if they require long forecasts, $t$ up to the maximum attainable is used. At those levels, the estimates here approach the limits set by three dimensional effects, which can be addressed with this approach but are beyond the scope of this paper. 
1 E. Teller, L. Wood, R. Hyde, M. Ishikawa, A. Ledebuhr, C. Leith, J. Nuckolls, and G. Canavan, "Long-Range Weather Predictions Enabled by Probing of the Atmosphere at High Space-Time Resolution," LLNL Report., August 1998.

2 G. Canavan, "Discussion of Long-Range Weather Prediction," Los Alamos Report LA-UR-98-4087, September 1998.

3 . G. Canavan, "Discussion of Long-Range Weather Prediction," Los Alamos National Laboratory report LA-UR-98-4087.

4 C. Leith and R. Kraichnan, "Predictability of Turbulent Flows," Journal of Atmospheric Sciences, Vol. 29, No. 6, Sept 1972, 1041-1058.

5 . G. Canavan, "Scaling Considerations for Global Weather Sensors, Los Alamos National Laboratory report LA-UR-98-5673, 11 Dec 1998.

6 E. Teller, et. Al., "Long-Range Weather Predictions Enabled by Probing of the Atmosphere at High Space-Time Resolution," op. cit. 


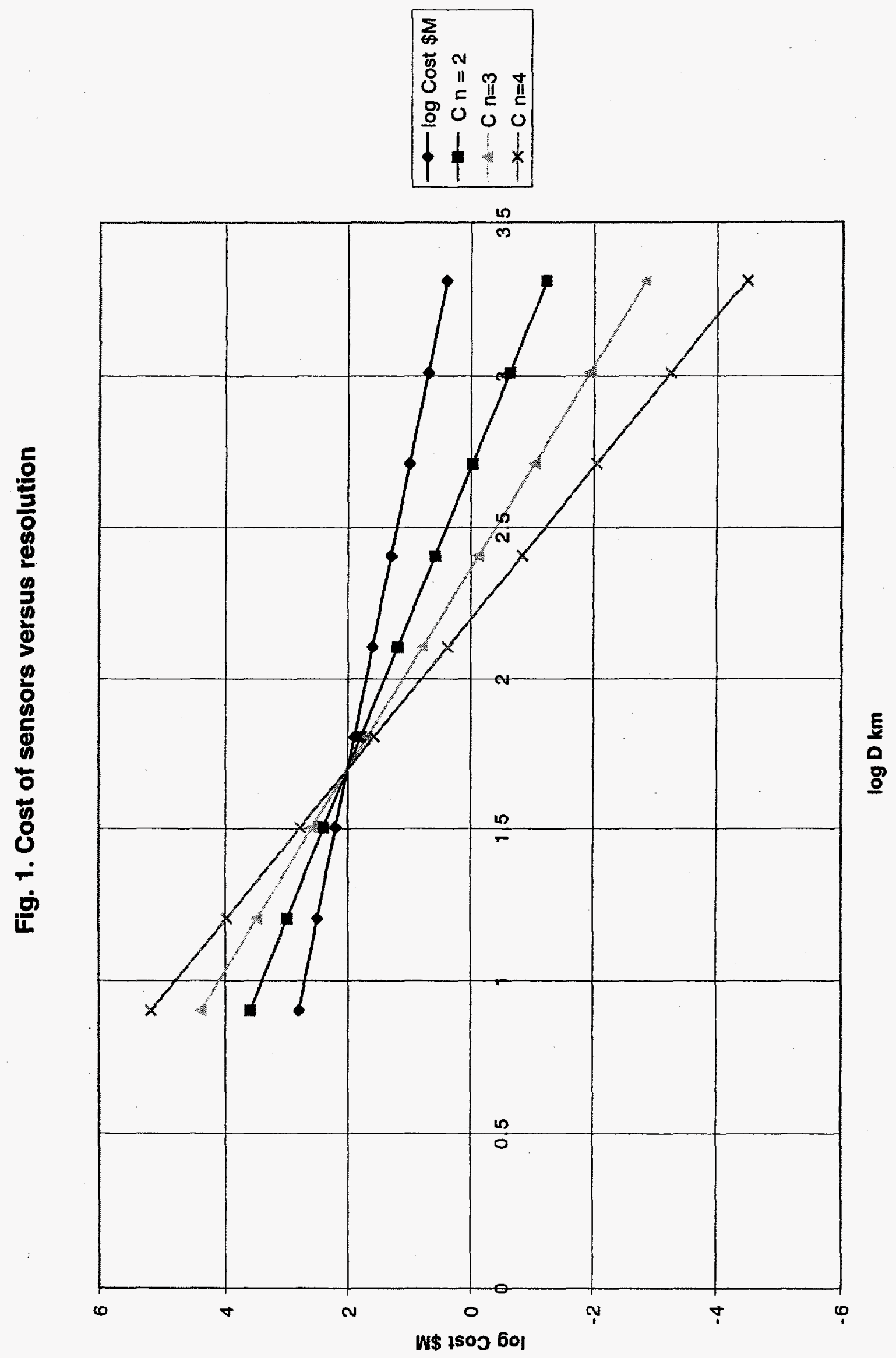




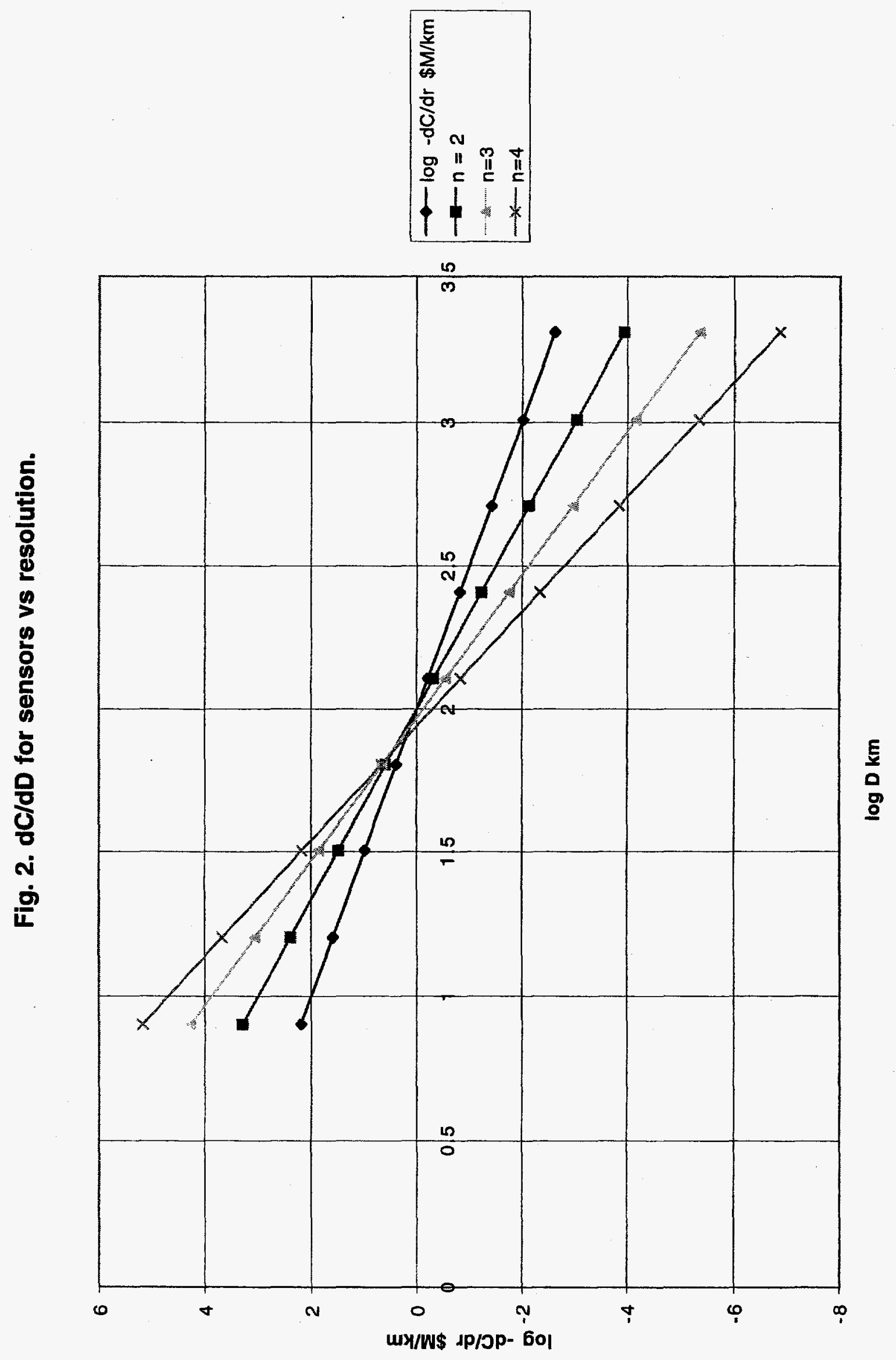




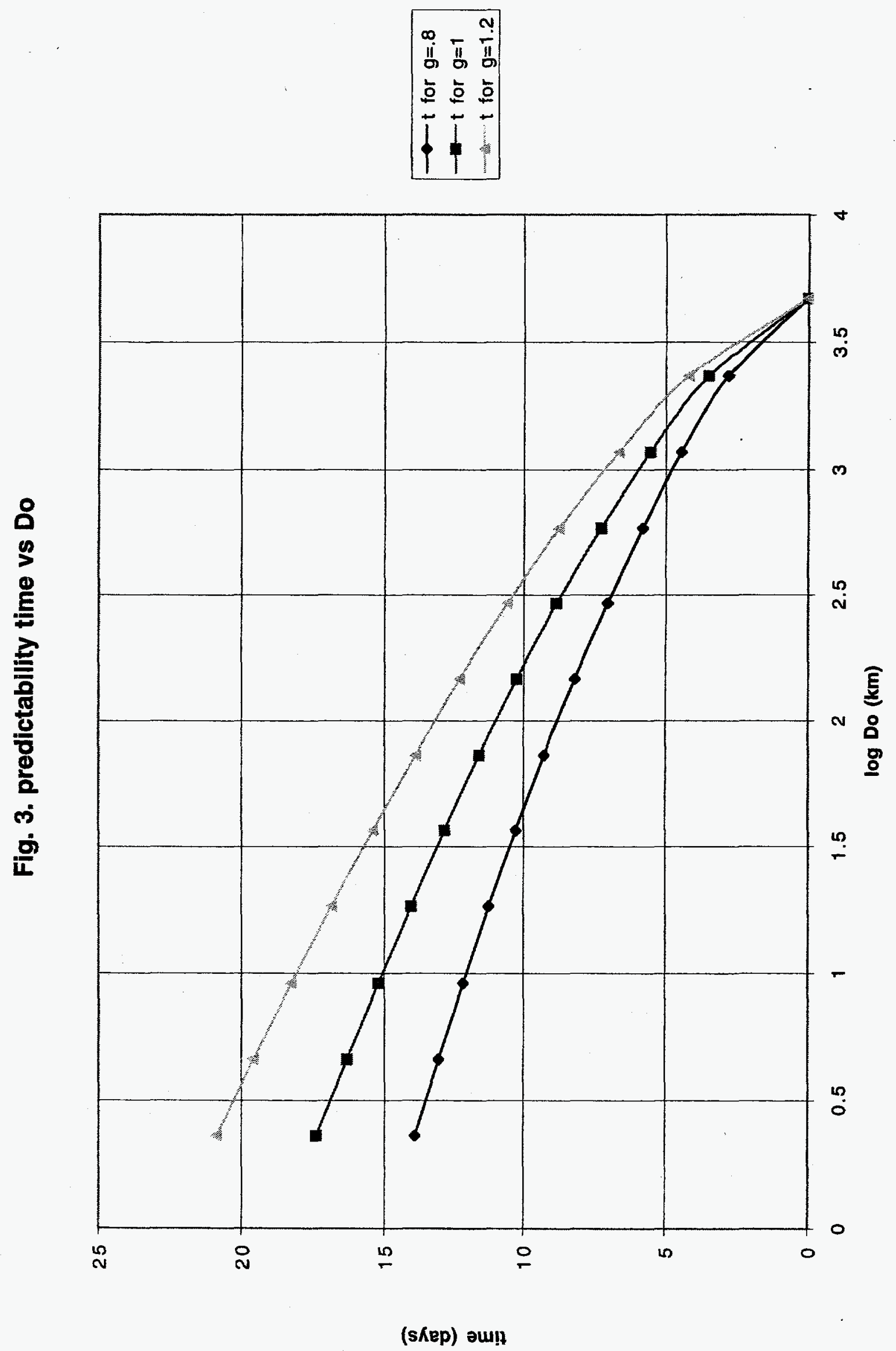




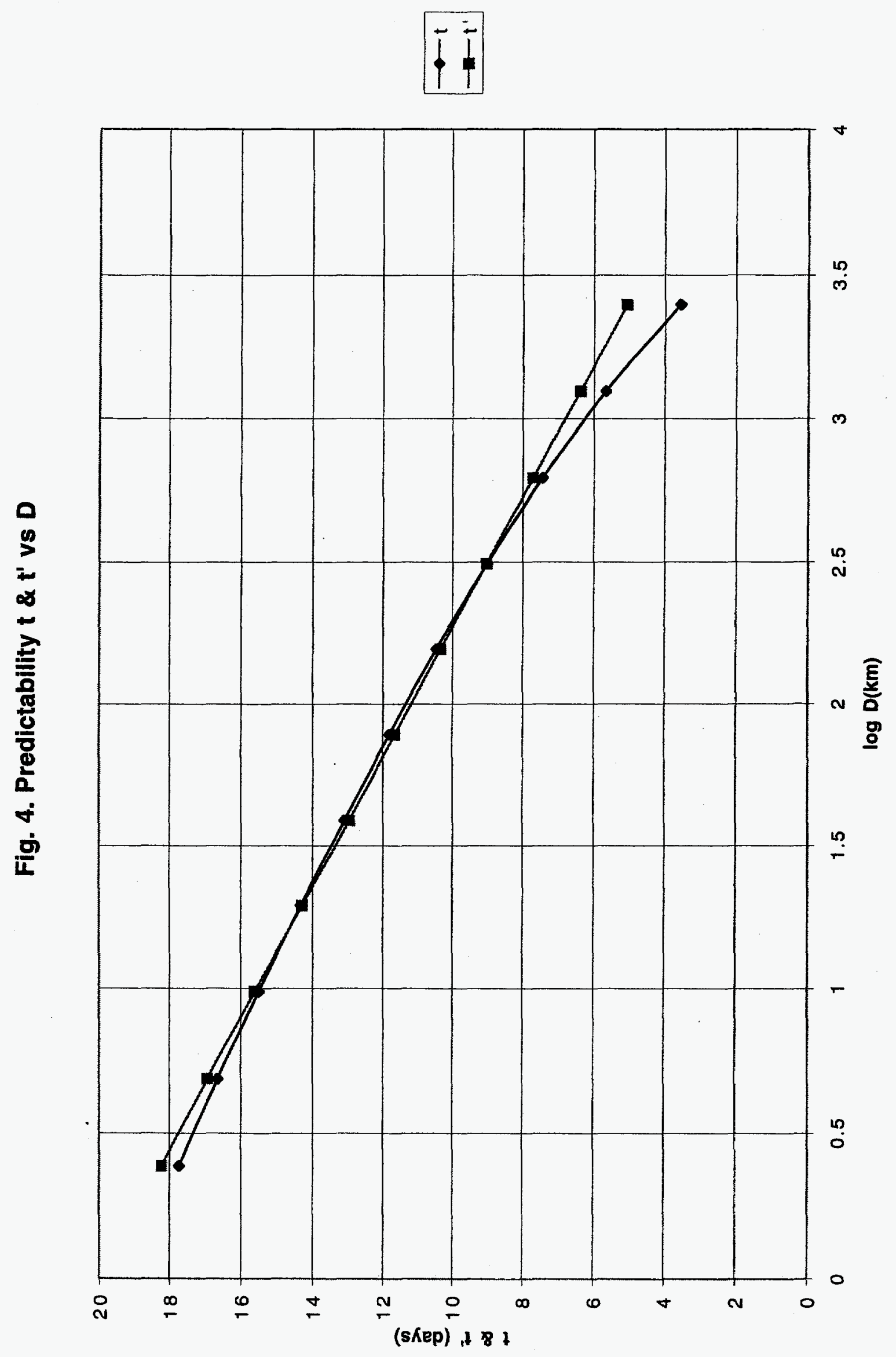




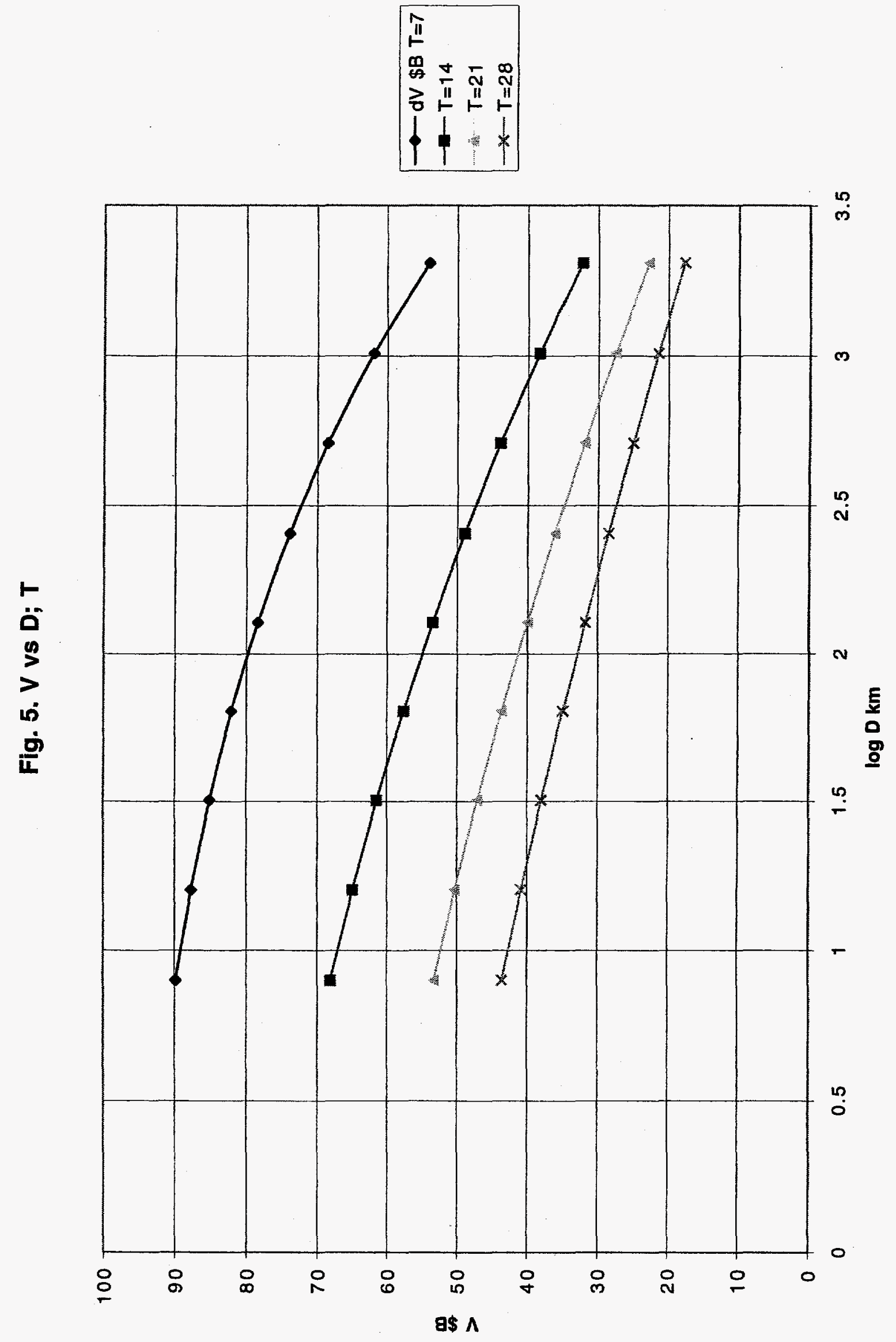




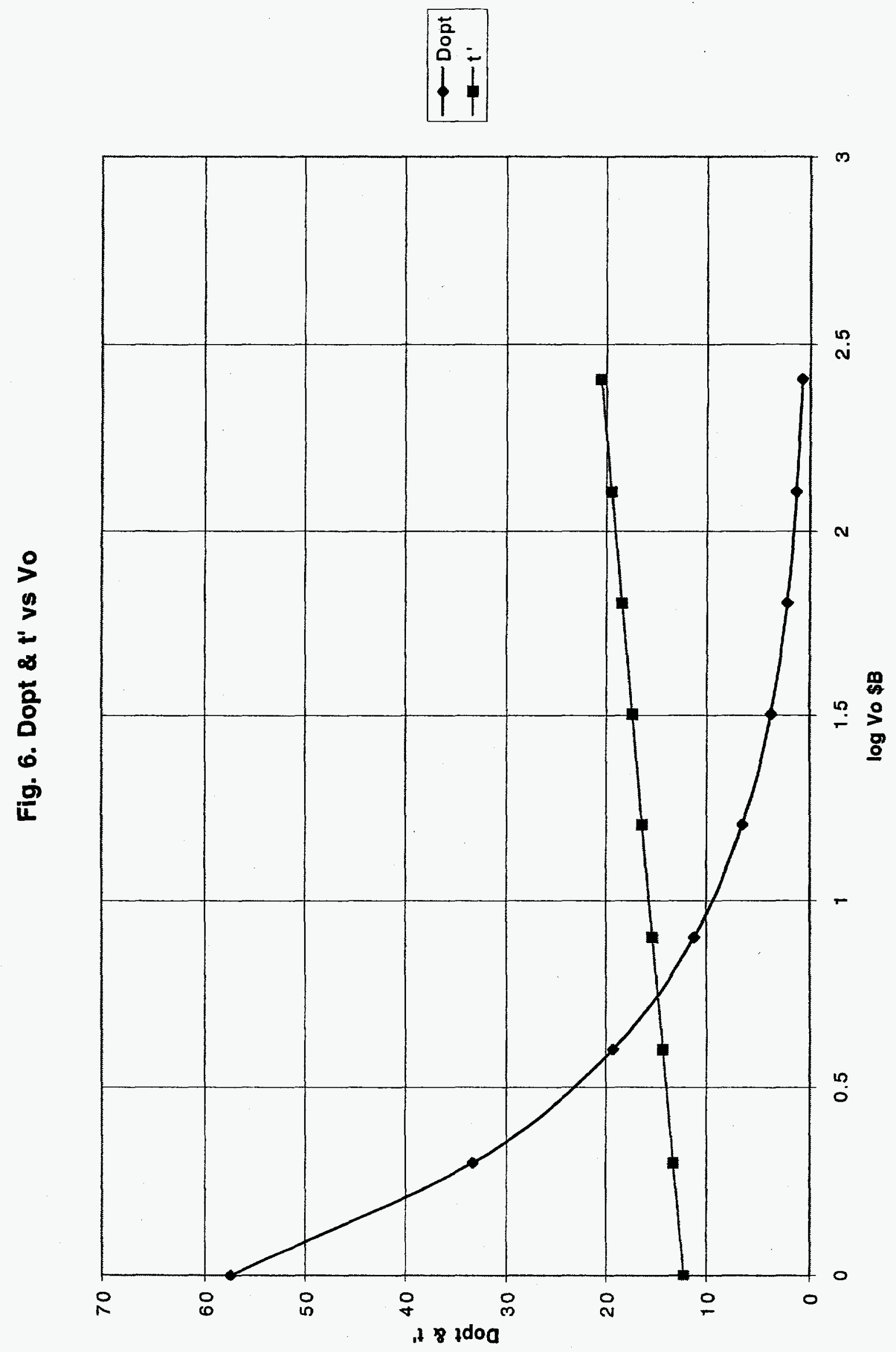




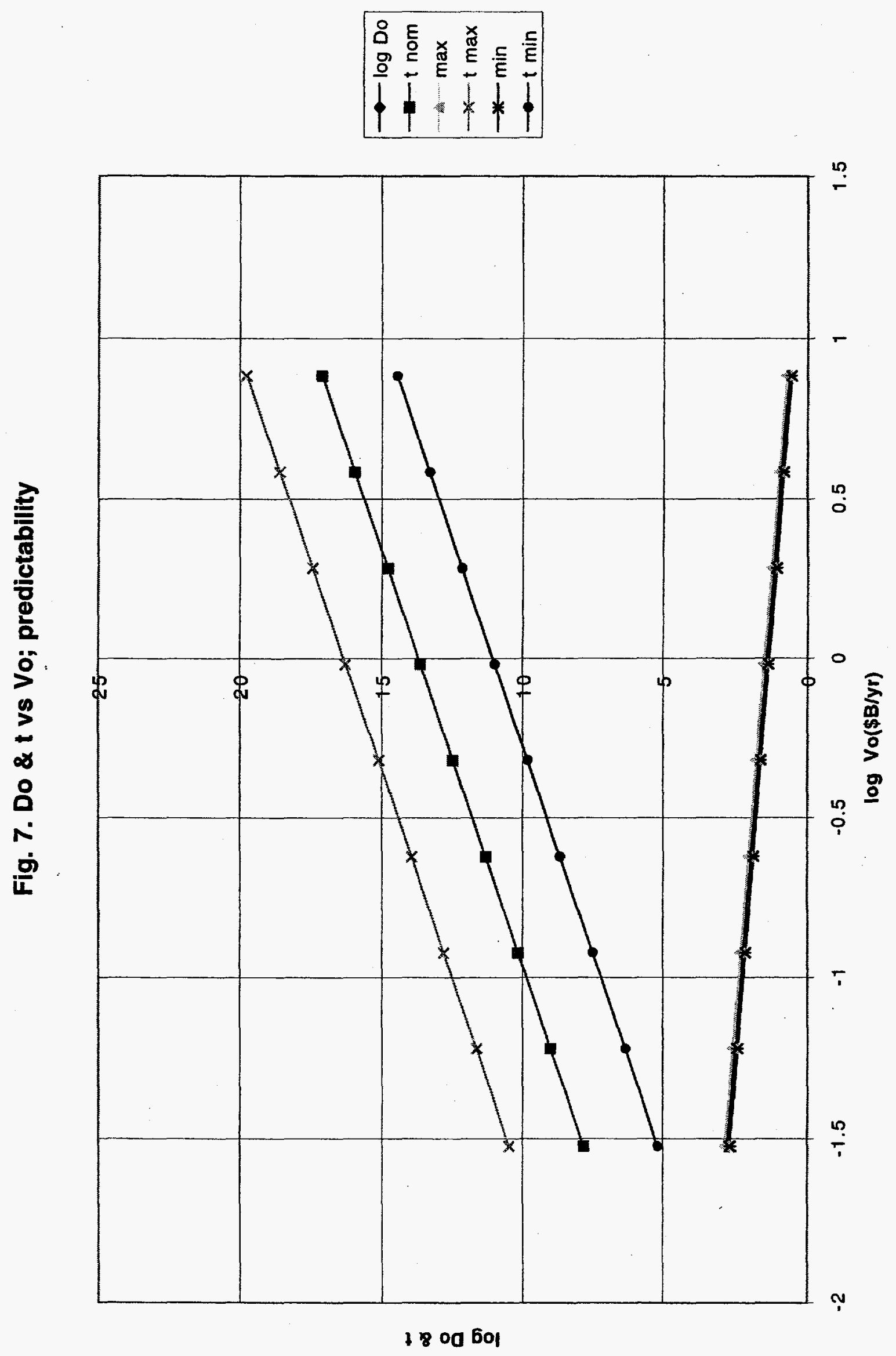




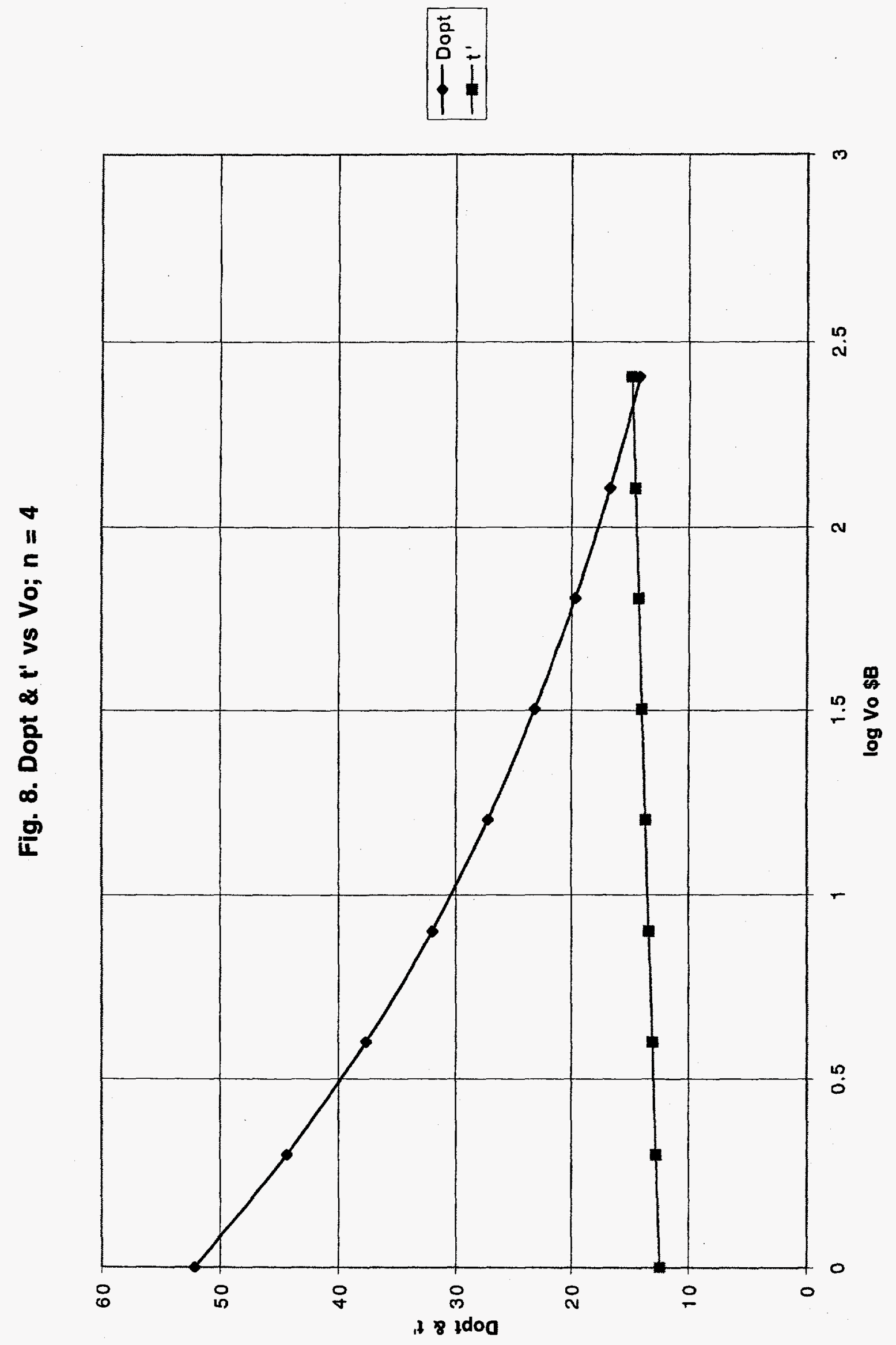




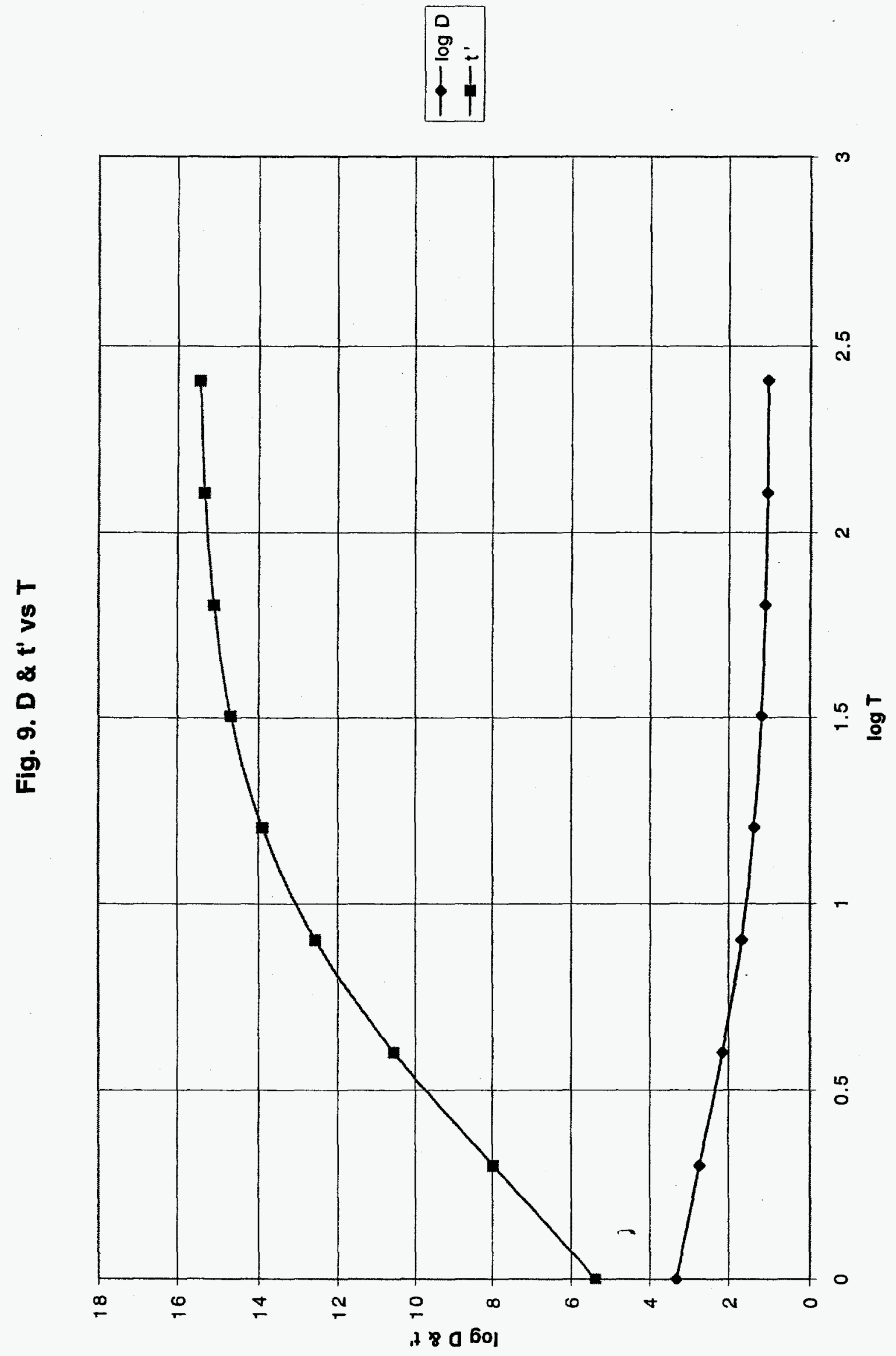




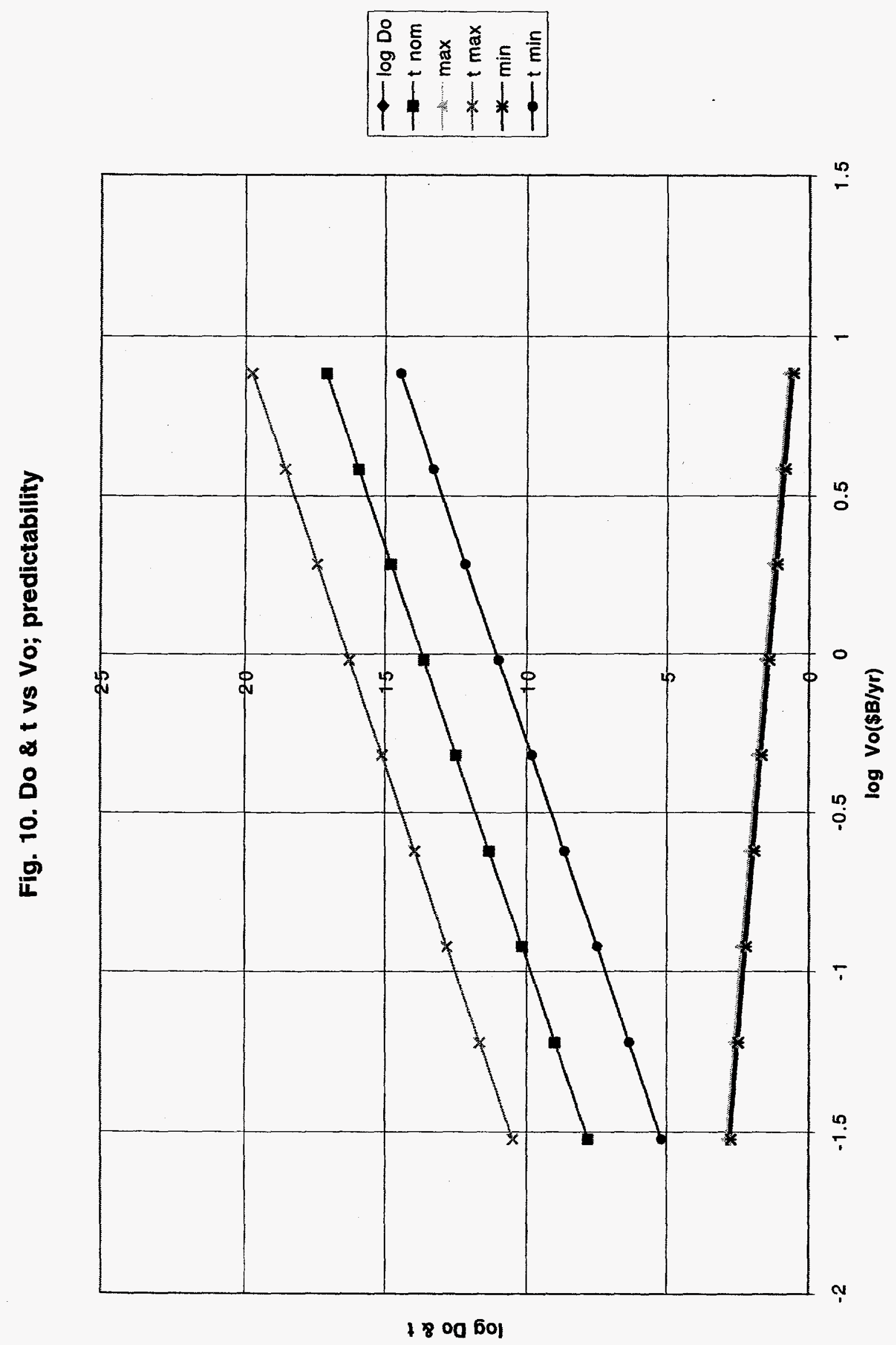

